\title{
Increase of hospital mortality in patients on mechanical ventilation in the biennium 2012-2013: an observational study
}

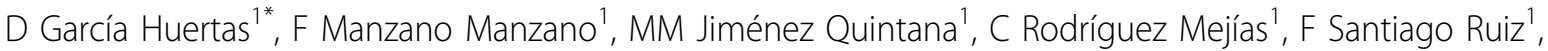 \\ F Villagrán Ramírez', A Ruiz Perea', M Colmenero Ruiz²
}

From ESICM LIVES 2015

Berlin, Germany. 3-7 October 2015

\section{Introduction}

A large number of patients in intensive care unit (ICU) require mechanical ventilation (MV) due to various conditions and have a high mortality. To reduce the high mortality, identification of risk factors is important, as well as temporary evolution of mortality.

\section{Objectives}

To evaluate the relationship between two periods of time and hospital mortality in patients requiring MV in an ICU.

\section{Methods}

A prospective, single-center, observational study was undertaken in patients under $\mathrm{MV} \geq 24 \mathrm{~h}$ in two periods (2010-2011 and 2012-2013) in the 26-beds medicalsurgical ICU at the Virgen de las Nieves University Hospital of Granada (Spain). Primary outcome measurement was hospital mortality. The main independent variable was the period 2010-2011and 2012-2013. Other variables were APACHE II score, gender, age, surgery, hepatic cirrhosis, neoplasia, cause, duration of MV, and length of stay in ICU. Hazard ratio (HR) of hospital mortality were calculated.

\section{Result}

The study included 845 patients (371 in first period and 474 in second period). Baseline characteristics were similar between groups. Hospital mortality was significantly higher in the second to the first period: $50.4 \%(239 / 474)$ vs 43.7\% (162/371) (non-adjusted HR 1.45, 95\% CI, 1.17-1.79, $\mathrm{p}<0.001)$. In the multivariate adjusted model the period
2012-2013 in comparison with the period 2010-2011 was a significant independent predictor of hospital mortality (adjusted HR, 1.60; 95\% CI, 1.21 to 2.12 ; $\mathrm{p}=0.005$ ). APACHE II score (1.07; 95\% CI, 1.07 to 1.09 ; $\mathrm{p}<0.001)$, age $(1.011 ; 95 \% \mathrm{CI}, 1.001$ to $1.022 ; \mathrm{p}=<0.001)$, neoplasia (1.47; 95\% CI, 1.008 to $2.15 ; \mathrm{p}=0.045)$, hepatic cirrhosis $(1.78$; $95 \% \mathrm{CI}, 1.08$ to $2.95 ; \mathrm{p}=0.02)$, and surgery admission $(0.52 ; 95 \% \mathrm{CI}, 0.33$ to $0.81 ; \mathrm{p}=0.004)$, were also in the model.

\section{Conclusions}

In our research, hospital mortality in patients under mechanical ventilation is high. Additionally, an increase in mortality has been identified in the last biennium of unknown cause.

\section{Authors' details}

${ }^{1}$ Hospital Virgen de las Nieves, Granada, Spain. ${ }^{2}$ Hospital Universitario San Cecilio, Granada, Spain.

Published: 1 October 2015

doi:10.1186/2197-425X-3-S1-A524

Cite this article as: García Huertas et al:: Increase of hospital mortality in patients on mechanical ventilation in the biennium 2012-2013: an observational study. Intensive Care Medicine Experimental 2015 3(Suppl 1):A524 